\title{
Primary scene responses by Helicopter Emergency Medical Services in New South Wales Australia 2008-2009
}

Colman B Taylor ${ }^{1,2^{*}}$, Bette Liü ${ }^{3}$, Eleanor Bruce ${ }^{4}$, Brian Burns ${ }^{5}$, Stephen Jan ${ }^{1}$ and John Myburgh ${ }^{1,3}$

\begin{abstract}
Background: Despite numerous studies evaluating the benefits of Helicopter Emergency Medical Services (HEMS) in primary scene responses, little information exists on the scope of HEMS activities in Australia. We describe HEMS primary scene responses with respect to the time taken, the distances travelled relative to the closest designated trauma hospital and the receiving hospital; as well as the clinical characteristics of patients attended.

Methods: Clinical service data were retrospectively obtained from three HEMS in New South Wales between July 2008 and June 2009. All available primary scene response data were extracted and examined. Geographic Information System (GIS) based network analysis was used to estimate hypothetical ground transport distances from the locality of each primary scene response to firstly the closest designated trauma hospital and secondly the receiving hospital. Predictors of bypassing the closest designated trauma hospital were analysed using logistic regression.

Results: Analyses included 596 primary missions. Overall the HEMS had a median return trip time of 94min including a median of $9 \mathrm{~min}$ for activation, 34min travelling to the scene, 30min on-scene and $25 \mathrm{~min}$ transporting patients to the receiving hospital. $72 \%$ of missions were within $100 \mathrm{~km}$ of the receiving hospital and $87 \%$ of missions were in areas classified as 'major cities' or 'inner regional'. The majority of incidents attended by HEMS were trauma-related, with road trauma the predominant cause (44\%). The majority of trauma patients (81\%) had normal physiology at HEMS arrival (RTS $=7.84$ ). We found $62 \%$ of missions bypassed the closest designated trauma hospital. Multivariate predictors of bypass included: age; presence of spinal or burns trauma; the level of the closest designated trauma hospital; the transporting HEMS.
\end{abstract}

Conclusion: Our results document the large distances travelled by HEMS in NSW, especially in rural areas. The high proportion of HEMS missions that bypass the closest designated trauma hospital is a seldom mentioned benefit of HEMS transport. These results along with the characteristics of patients attended and the time HEMS take to complete primary scene responses are useful in understanding the benefit HEMS provides and the services it replaces.

Keywords: Wounds and injury, Trauma systems, Helicopter Emergency Medical Services, Patient acuity, Cost, Reimbursement

\footnotetext{
* Correspondence: ctaylor@georgeinstitute.org.au

${ }^{1}$ The George Institute for Global Health, PO Box M201, Missenden Rd Camperdown, NSW 2050, Sydney, NSW, Australia

${ }^{2}$ The University of Sydney, Sydney Medical School, Sydney, NSW, Australia

Full list of author information is available at the end of the article
} 


\section{Background}

In New South Wales (NSW) Australia, Helicopter Emergency Medical Services (HEMS) undertake primary scene responses and secondary inter-facility transfers as part of the state trauma plan and critical care networks $[1,2]$.

Compared to road transport systems, there are three predominant advantages of using HEMS for a primary scene response. They include faster transport to definitive care, access to patients where limited infrastructure precludes timely road access, and direct delivery to the patient of advanced life-saving critical skills by a specialty trained physician or paramedic. During patient transport, a further advantage of HEMS is the ability to bypass regional hospitals and transfer patients directly to hospitals which have appropriate facilities, as per local trauma treatment guidelines [2]. In NSW, a HEMS primary response is recommended in scenarios including difficult patient access (e.g. cliff fall or water rescue), where the patient condition requires specialised interventions (e.g. rapid sequence intubation) or situations where a helicopter will provide a more expedient response and transport $[3,4]$. In spite of its high costs, recent evidence indicates that HEMS are potentially cost-effective [5] but this is dependent on the accuracy of triage [6].

To understand the role of HEMS as a distinct intervention in primary scene responses, it is necessary to evaluate the effect of HEMS on patient outcome, compared to conventional ground transport [7-11]. However there are many challenges to such studies as HEMS encompass many aspects such as decreasing the time to definitive care (logistics), and rapidly providing potentially life-saving critical interventions. Both within and between jurisdictions, HEMS are also known to vary in aspects such as staffing and skill levels, range of operations (e.g. pre-hospital care, inter-hospital retrieval and SAR) and the types of patients attended. Therefore, to understand how a HEMS may benefit patients from primary scene responses in NSW, a fundamental step is to provide an understanding of HEMS operations with respect to the key time performance indicators, the proximity of operations to the destination hospital and the types of the patients attended. Further, although HEMS are known to travel large distances, the proportion of missions which bypass closer designated trauma hospitals has not been previously estimated in NSW.

\section{Aim}

The aim of this study was to document the scope of HEMS primary scene responses in NSW with respect to the time taken, the distances travelled and the clinical characteristics of patients attended. Additionally, this study examines the proportion of missions which bypass the closest designated trauma hospital and the predictors of hospital bypass.

\section{Methods}

\section{Setting}

The state of NSW is situated on the east coast of Australia and is characterized by a large land mass (over 800,000 Square $\mathrm{Km}$ ) and a population of approximately 6.8 million people, who predominantly reside near coastal areas. The capital city is Sydney which incorporates approximately two thirds of the population of NSW (approximately 4.5 million). As of the 1st July 2008, the NSW trauma care system incorporated a networked system of 23 designated trauma hospitals, which were classified as either major adult $(n=9)$, major paediatric $(n=3)$, regional $(n=2)$ or rural regional $(n=10)$ according to available resources [2]. During this time, nine HEMS operated in NSW, performing primary scene responses and secondary inter-facility transfers as part of the NSW trauma system. HEMS are activated by service protocols according to MIST criteria (Mechanism of injury; Injuries sustained; physiological Signs and symptoms; Transport time) or via a rapid launch coordinator. Three HEMS are located in the Sydney metropolitan and the remaining six HEMS are located in regional areas of NSW [12]. One of the metropolitan services operated a separate rapid response trauma-only service as part of an ongoing clinical trial [13].

\section{Data collection}

This study was approved by the Sydney South West Area Health Service HREC. We performed a retrospective cross-sectional analysis of clinical service data for primary scene responses collected by three HEMS (Greater Sydney Area HEMS) in NSW for the period $1^{\text {st }}$ July 2008 through $30^{\text {th }}$ June 2009 operated by the Ambulance Service of NSW.

Clinical service and key timing data are collected by each HEMS service in NSW for each patient attended to by a HEMS crew. Data are usually recorded by the medical crew during the mission and then transcribed contemporaneously onto case sheets. These are entered into a database following the mission. Data fields include date of transport; components of transport time (e.g. time trip is activated; time arrived at patient); mission type (primary scene response or secondary inter-facility transport); patient diagnosis categories; transport origin and destination; and clinical interventions undertaken by HEMS staff. Patient clinical observation data are also collected from time of patient contact until stretcher offload on completion of the mission.

Of the nine HEMS operating in NSW during the reference period, consistent clinical service data for primary scene responses were available in four HEMS only. This 
included two HEMS based in the Sydney metropolitan area (Metro1 \& Metro2) and two HEMS located in regional population centres (Regional1 and Regional2). Three HEMS were operated by the same provider (Greater Sydney Area HEMS). One of the metropolitan HEMS (Metro2) with consistent data was operated by Careflight Ltd. During the study period, the CareFlight HEMS was solely operating within the confines of a head injury trial (HIRT) and was therefore excluded.

\section{Hypothetical ground transport distance estimation and remoteness classification}

For each HEMS primary scene response we estimated a corresponding hypothetical ground transport distance, using a Geographic Information Systems (GIS) based network analysis. Response locations were mapped using Google Earth and imported into the GIS. A road network layer was compiled using GEODATA TOPO 250k Map Series (Geoscience Australia) to model vehicle transport routes. The ArcGIS 9.3.1 Network Analysis extension was used to model the travel distance between each incident location and firstly the nearest designated trauma hospital and secondly the receiving trauma hospital based on the optimal travel route. In identifying optimal travel routes, travel impedance factors (e.g. gravel roads) were established to account for variability in travel speed associated with the road type.

To assess the 'remoteness' of the populations serviced by each HEMS we used the enhanced Accessibility/ Remoteness Index of Australia (ARIA+) score [14]. The ARIA+ scores localities according to their proximity to service centres using a continuous scale from 0 (high accessibility) to 15 (high remoteness). Scores can be further classified into 5 major categories: major cities, inner regional, outer regional, remote and very remote. We recorded the proportion of responses in each ARIA+ category according to the postcodes attended by each HEMS during the 2008/2009 financial year.

\section{Data analysis}

Data were analysed using SAS version 9.2. For the analysis of HEMS time and distance we included only primary scene responses categorised as 'emergency' as these correspond to time critical missions that require a rapid response. We also excluded missions requiring a winch as we assumed these missions can only be completed by HEMS (and ground distance was unable to be calculated). For each HEMS primary scene response the following times were calculated: activation time (time between activation call received and helicopter departure from base to the scene), response time (time between departure from base to arrival at scene), scene time (time between arriving at the patient and departing the scene for destination hospital), transport time (time between departing the scene and arriving at destination hospital) and total time (time between activation call received and arriving at destination hospital).

We described patient demographics, clinical characteristics and diagnostic groups for all primary scene responses. We defined trauma patients according to the incident recorded in the service database, such as 'motor vehicle accident' or 'fall'. For trauma patients, we described the types of trauma sustained (such as chest or head trauma) according to the APACHE III sub-diagnosis recorded in the HEMS database [15]. For non-trauma patients, diagnoses were described according to the APACHE III titles (such as cardiovascular or metabolic).

Continuous variables including age, Glasgow Coma Score (GCS) [16] and Revised Trauma Score (RTS) [17] were categorised according to standard definitions. The association between potential predictors such as type of trauma sustained and whether or not patients were taken to the closest designated trauma hospital were analysed using stepwise logistic regression. Each potential predictor was firstly examined in a univariate model and factors with a predetermined level of significance $(\mathrm{p}<0.1)$ were then entered into a multivariate model.

\section{Results}

During the reference period, a total of 596 primary scene responses were identified from clinical service data in the three HEMS. The metropolitan HEMS undertook more missions $(\mathrm{N}=411,69 \%)$ than the Regional HEMS (Regional1 N=102, 17\%; Regional2 N=83, 14\%). After excluding non-emergency missions and winch missions, 464 primary scene responses were used to calculate distance and time (78\% of total missions [Metro1 HEMS $\mathrm{N}=308$, 66\%; Regional1 HEMS N=74, 16\%; Regional2 HEMS N=82, 18\%]).

Table 1 shows the mean and median time taken for the HEMS non-winch and emergency responses $(\mathrm{N}=464)$. Overall, a return trip took a median time of $94 \mathrm{~min}$. Based on the inter-quartile range of each time component, between $5 \%-11 \%$ of time was spent in activation, between $27 \%-48 \%$ was spent travelling to the scene, between $21 \%-43 \%$ was spent on-scene and between $27 \%-37 \%$ was spent transporting the patient to the receiving hospital.

Table 1 Time categories for HEMS 'emergency' and nonwinch primary scene responses

\begin{tabular}{lrrr}
\hline Time Category & $\mathbf{N}$ & Median $\mathbf{m i n}($ IQR) & Mean $\boldsymbol{m i n}$ (SD) \\
\hline Activation & 464 & $9(5-10)$ & $8.7(6.4)$ \\
Response & 464 & $34(25-45)$ & $38.7(21.4)$ \\
Scene & 464 & $30(20-40)$ & $34.7(22.3)$ \\
Transport & 450 & $25(19-35)$ & $29.6(23.4)$ \\
Total & 450 & $94(75-115)$ & $102.4(48.1)$ \\
\hline
\end{tabular}


Our data allowed us to estimate the road distance from the response location to the nearest designated trauma hospital and the actual receiving hospital for 425 $(92 \%)$ and $406(88 \%)$ primary scene responses respectively (Figure 1). For the 406 missions in which we had information on the receiving hospital, we found HEMS bypassed the closest designated trauma hospital in $62 \%$ of cases $(\mathrm{N}=406)$.

Table 2 shows the patient and HEMS characteristics that were associated with bypassing the closest designated trauma hospital. In univariate analyses we found classification of spinal or burns trauma, along with age, GCS, the level of closest designated trauma hospital and the service all met the pre-defined level of significance $(\mathrm{P}<0.1)$ and were therefore included in a multivariate model. After adjusting for all factors in the multivariate analysis, results showed patients with spinal or burns trauma were less likely to be taken to the closest hospital compared to patients without both these types of trauma (OR: $0.47 \mathrm{p}=0.055$ [spinal]; OR: $0.13 \mathrm{p}=0.046$ [burns]). Regarding age, results showed paediatric patients $(<=16$ years) were less likely to be taken to the closest hospital compared to adult patients (OR: 0.48; $\mathrm{p}=0.042$ ). We also found the level of closest designated trauma hospital was a highly significant predictor of bypass $(\mathrm{p}<0.0001)$ with patients less likely to be taken to the closest hospital if it was classified as regional (OR: 0.16) and rural regional (OR 0.09) compared to hospitals classified as major trauma. Finally, the individual HEMS transporting the patient also predicted hospital bypass with both Regional1 and Regional2 more likely to take patients to the closest designated trauma hospital (OR: 3.61 \& 10.95; $\mathrm{p}<0.0001 \& 0.001$ respectively) compared to Metro1.

Figure 2 shows that the metropolitan HEMS transported the majority of their patients to a hospital within $100 \mathrm{~km}$ of the scene (Metro1: 85\%), where in contrast, the regional HEMS transported a higher proportion of patients to a hospital that was greater than $100 \mathrm{~km}$ from the scene (Regional1: 46\%; Regional2: 63\% respectively). Metro1 travelled a median distance of $44 \mathrm{~km}$ (IQR: 24$78 \mathrm{~km})$ to the receiving hospital whereas Regional1 and Regional2 travelled median distances of $94 \mathrm{~km}$ (IQR: $54-$ $131 \mathrm{~km}$ ) and $114 \mathrm{~km}$ (IQR: $83-180 \mathrm{~km}$ ) to the receiving hospital respectively.

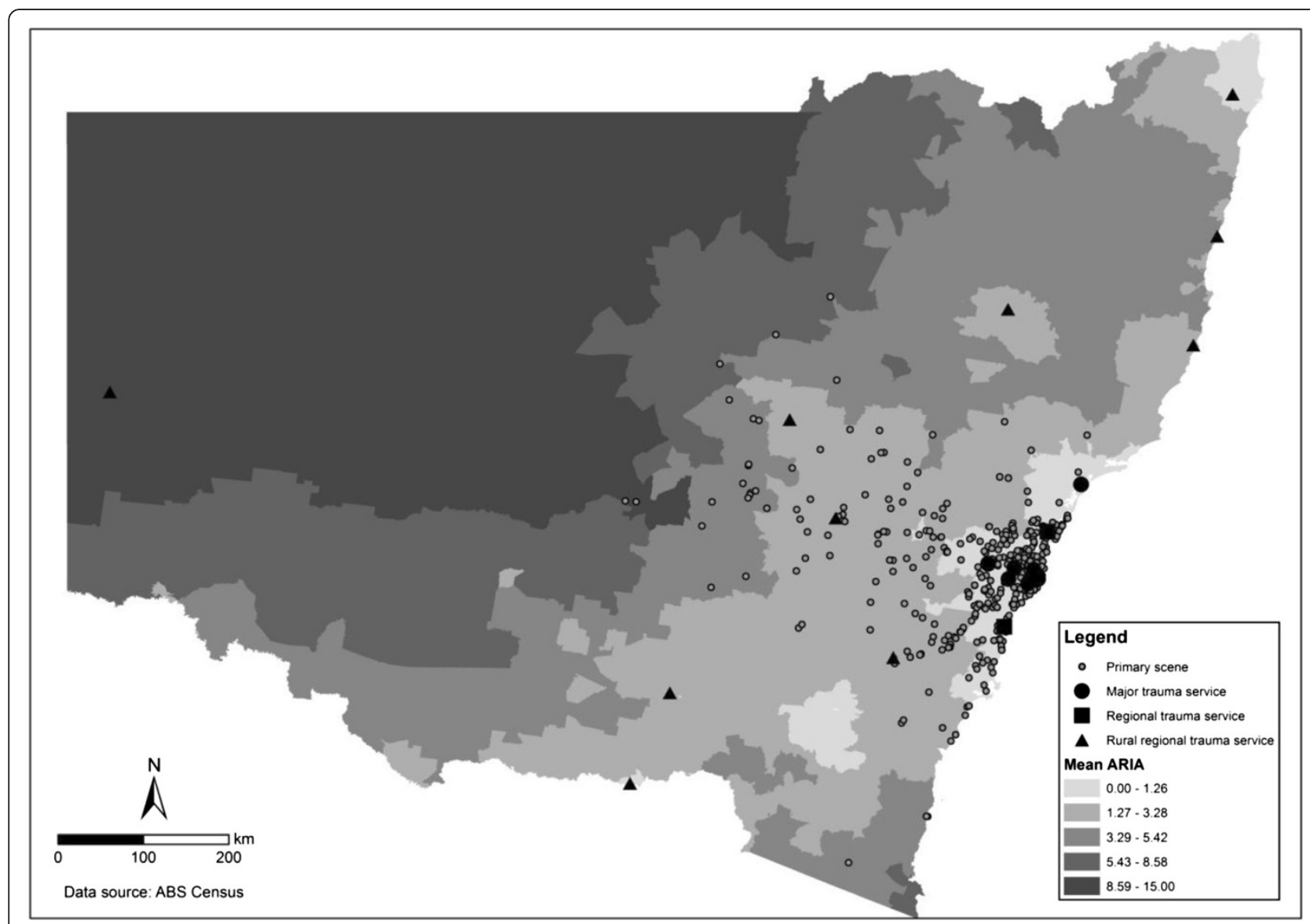

Figure 1 Map of NSW including remoteness index (ARIA+), trauma services and location of primary scene responses during July 2008 to June 2009. 
Table 2 Univariate and multivariate predictors of HEMS transports being taken to the closest designated trauma hospital

\begin{tabular}{|c|c|c|c|c|c|c|}
\hline Predictor & Category & $\mathrm{N}$ closest/total & $\%$ & Univariate OR $(95 \% \mathrm{Cl})$ & Multivariate OR $(95 \% \mathrm{Cl})$ & Multivariate $p$-value \\
\hline \multirow[t]{2}{*}{ CHEST TRAUMA } & YES & $22 / 55$ & $40.0 \%$ & $1.09(0.61-1.95)$ & & \\
\hline & NO & $133 / 351$ & $37.9 \%$ & 1.00 & & \\
\hline \multirow[t]{2}{*}{ HEAD TRAUMA } & YES & $50 / 143$ & $35.0 \%$ & $0.81(0.53-1.24)$ & & \\
\hline & NO & $105 / 263$ & $39.9 \%$ & 1.00 & & \\
\hline \multirow[t]{2}{*}{ SPINAL TRAUMA } & YES & $22 / 80$ & $27.5 \%$ & $0.55(0.32-0.94)$ & $0.47(0.22-0.99)$ & $p=0.055$ \\
\hline & NO & $133 / 326$ & $40.8 \%$ & 1.00 & 1.00 & \\
\hline \multirow[t]{2}{*}{ BURNS } & YES & $1 / 10$ & $10.0 \%$ & $0.18(0.02-1.39)$ & $0.13(0.02-1.05)$ & $p=0.046$ \\
\hline & NO & $154 / 396$ & $38.9 \%$ & 1.00 & 1.00 & \\
\hline \multirow[t]{2}{*}{$\mathrm{AGE}^{1}$} & $<=16$ & $18 / 64$ & $28.1 \%$ & $0.58(0.33-1.05)$ & $0.48(0.24-0.97)$ & $p=0.042$ \\
\hline & $17+$ & $136 / 339$ & $40.1 \%$ & 1.00 & 1.00 & \\
\hline \multirow[t]{2}{*}{$\mathrm{GCS}^{2}$} & $3-8$ & $9 / 39$ & $23.1 \%$ & $0.46(0.21-0.99)$ & $0.57(0.23-1.4)$ & $p=0.219$ \\
\hline & $9-15$ & $143 / 361$ & $39.6 \%$ & 1.00 & 1.00 & \\
\hline \multirow[t]{2}{*}{$\mathrm{RTS}^{3}$} & $<7.84$ & $18 / 64$ & $28.1 \%$ & $0.75(0.44-1.27)$ & & \\
\hline & 7.84 & $115 / 294$ & $39.1 \%$ & 1.00 & & \\
\hline \multirow[t]{3}{*}{ CLOSEST HOSPITAL } & MAJOR & $102 / 208$ & $49.0 \%$ & 1.00 & 1.00 & \\
\hline & REGIONAL & $21 / 104$ & $20.2 \%$ & $0.26(0.15-0.46)$ & $0.16(0.08-0.32)$ & $p<0.0001$ \\
\hline & RURAL REGIONAL & $32 / 94$ & $34.0 \%$ & $0.54(0.32-0.89)$ & $0.09(0.03-0.24)$ & $p<0.0001$ \\
\hline \multirow[t]{3}{*}{ SERVICE } & Metro1 & $93 / 271$ & $34.3 \%$ & 1.00 & 1.00 & \\
\hline & Regional1 & $26 / 68$ & $38.2 \%$ & $1.19(0.68-2.05)$ & $3.61(1.7-7.68)$ & $p<0.0001$ \\
\hline & Regional2 & $36 / 67$ & $53.7 \%$ & $2.22(1.29-3.82)$ & $10.95(3.75-31.99)$ & $p=0.001$ \\
\hline
\end{tabular}

$\mathrm{N}=3$ missing.

$\mathrm{N}=6$ missing

$\mathrm{N}=32$ missing.

Figure 3 provides an overview of the remoteness of HEMS activities. Primary scene responses for the metropolitan HEMS were predominately classified as either 'major cities' or 'inner regional'. In contrast, Regional2

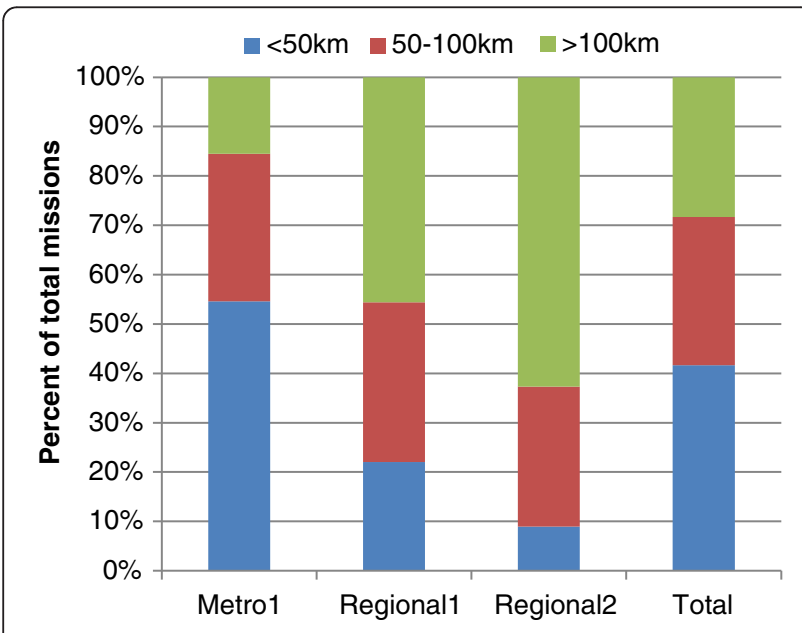

Figure 2 Proportion of primary scene responses within estimated distance categories to the receiving hospital stratified by service.
HEMS responded to a majority of localities classified as 'outer regional' or 'inner regional'.

Table 3 provides an overview of all patients attended by HEMS (including non-emergency and winch missions; $\mathrm{N}=596)$. The majority of patients were male $(\mathrm{n}=434,74 \%)$ and adults with $13 \%(\mathrm{~N}=78)$ aged over 60 (median age: 37; IQR: 20-51). In terms of primary scene responses attended by HEMS, most were trauma related $(\mathrm{N}=555,93 \%)$ with road trauma the predominant cause of trauma-related incidents $(\mathrm{N}=259,47 \%)$. For trauma patients, injuries to the extremities were the most common $(\mathrm{N}=238,31 \%)$.

Table 3 also shows patient clinical condition as judged by the attending clinician as well as patient physiology at arrival. We found $2 \%$ of patients $(\mathrm{N}=9)$ were dead on arrival of the HEMS team with a further $2 \%(\mathrm{~N}=11)$ dying post-arrival or en-route to hospital. The majority of patients were considered stable at arrival $(\mathrm{N}=474,80 \%)$, with the majority of these patients remaining stable ( $\mathrm{N}=466,98 \%$ of initially stable patients). Seventeen percent of patients $(\mathrm{N}=101)$ were considered unstable at arrival. For trauma patients (excluding patients who were dead on arrival), we found $73 \%$ of patients had a normal GCS score of $15(\mathrm{~N}=394)$. We were also able to calculate 


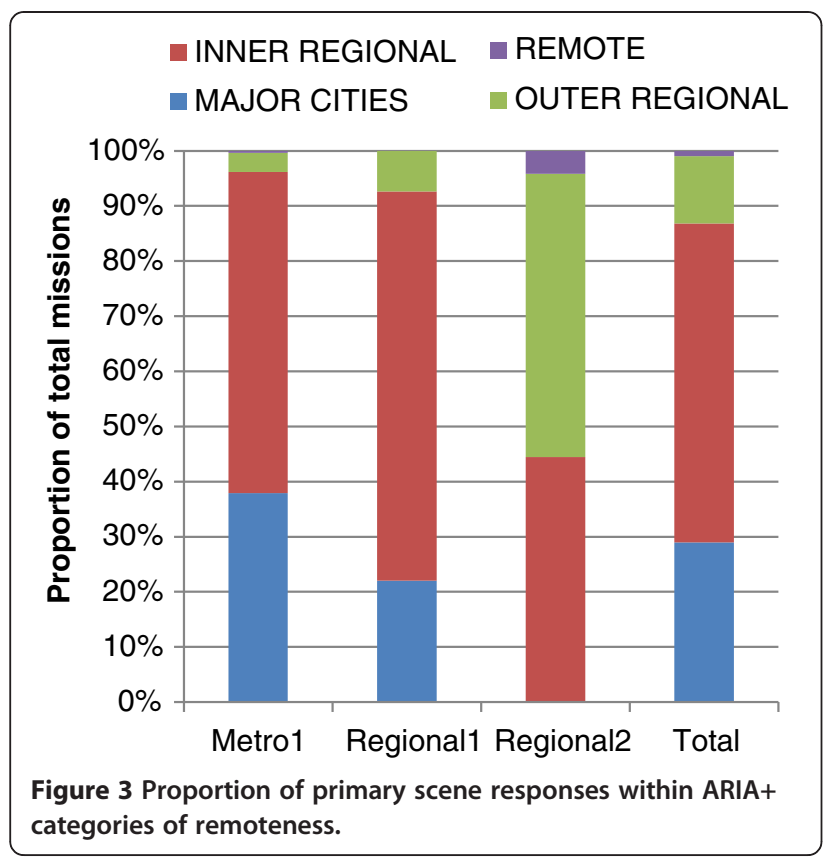

the Revised Trauma Score for 486 patients (88\% of trauma patients) with $81 \%$ of these patients recording a normal score of 7.84 $(\mathrm{N}=394)$.

Table 4 shows patient characteristics in relation to the clinical condition at arrival. For patients that died before or after the HEMS arrival or en-route to the hospital, we found a high proportion of non-trauma incidents (33\% and $46 \%$ respectively). The majority of these non-trauma responses were classified as due to cardiovascular events (22\% and $36 \%$ respectively) such as cardiac arrest.

\section{Discussion}

To date, this is the most comprehensive description of both metropolitan and regional HEMS primary scene responses in NSW which includes the time taken and the proximity of missions to the receiving hospital. Our results highlight the often large distances travelled by

Table 3 Characteristics of patients attended by HEMS in primary scene responses

\begin{tabular}{lr}
\hline Patient characteristics & $\mathbf{N}(\%)$ \\
\hline AGE & $(\mathrm{N}=589 ; 7$ missing) \\
$<=16$ & $89(15.1 \%)$ \\
$17-30$ & $162(27.5 \%)$ \\
$31-45$ & $147(25 \%)$ \\
$46-60$ & $113(19.2 \%)$ \\
$61+$ & $78(13.2 \%)$ \\
SEX & $(\mathrm{N}=590 ; 6$ missing) \\
MALE & $434(73.6 \%)$ \\
FEMALE & $156(26.4 \%)$
\end{tabular}

Table 3 Characteristics of patients attended by HEMS in primary scene responses (Continued)

\begin{tabular}{lr}
\hline INCIDENT & $(\mathrm{N}=596 ; 0$ missing $)$ \\
ROAD & $259(43.5 \%)$ \\
FALL & $110(18.5 \%)$ \\
SPORT & $66(11.1 \%)$ \\
OTHER & $71(11.9 \%)$ \\
UNKNOWN ${ }^{1}$ & $49(8.2 \%)$ \\
NON-TRAUMA & $41(6.9 \%)$
\end{tabular}

\section{PATIENT DIAGNOSIS}

TRAUMA DX ${ }^{2}$

$(\mathrm{N}=555 ; 0$ missing $)$

ABDOMEN

$23(3 \%)$

BURNS

$12(1.6 \%)$

CHEST

$70(9.2 \%)$

EXTREMITY

$238(31.4 \%)$

HEAD

$180(23.7 \%)$

MULTI

$115(15.2 \%)$

OTHER

$30(4 \%)$

PELVIS

$32(4.2 \%)$

SPINAL

$101(13.3 \%)$

NON-TRAUMA DX

( $N=40 ; 1$ missing)

CARDIOVASCULAR

$16(2 \%)$

GASTROINTESTINAL

$3(0.4 \%)$

METABOLIC

$7(1 \%)$

NEUROLOGIC

$3(0.4 \%)$

$8(1 \%)$

$3(0.4 \%)$

RESPIRATORY

CLINICAL CONDITION

( $N=595 ; 1$ missing)

DIED PRE ARRIVAL

$9(1.5 \%)$

DIED POST ARRIVAL OR ENROUTE

$11(1.9 \%)$

UNSTABLE INITIALLY AND DIDNT IMPROVE

$27(4.5 \%)$

UNSTABLE INITIALLY AND IMPORVED

STABLE INITIALLY AND DETERIORATED

$74(12.4 \%)$

$8(1.3 \%)$

STABLE THROUGHOUT

$466(78.3 \%)$

\section{PHYSIOLOGY ${ }^{3}$}

GCS

( $N=538 ; 58$ missing)

3-8

$57(10.6 \%)$

9-14

$87(16.2 \%)$

15

$394(73.2 \%)$

RTS

$(\mathrm{N}=486 ; 110$ missing)

$<7.84$

$92(18.9 \%)$

7.84

$394(81.1 \%)$

'Unknown' incidents included trauma related incidents such as head injuries where information regarding the incident is missing.

Patients with multiple injured body regions (e.g. Pelvis/Spinal Trauma) were listed in all identified body regions and hence percentages add to greater than 100.

Patients considered 'dead pre arrival' and non-trauma patients excluded. 
Table 4 Characteristics of patients stratified by clinical condition on arrival at the scene

\begin{tabular}{|c|c|c|c|c|c|c|c|c|c|c|c|c|c|c|}
\hline & \multicolumn{2}{|c|}{$\begin{array}{c}\text { Died } \\
\text { pre-arrival }\end{array}$} & \multicolumn{2}{|c|}{$\begin{array}{c}\text { Died } \\
\text { post-arrival }\end{array}$} & \multicolumn{2}{|c|}{$\begin{array}{c}\text { Unstable initially } \\
\text { and didn't improve }\end{array}$} & \multicolumn{2}{|c|}{$\begin{array}{c}\text { Unstable initially } \\
\text { and improved }\end{array}$} & \multicolumn{2}{|c|}{$\begin{array}{c}\text { Stable initially and } \\
\text { deteriorated }\end{array}$} & \multicolumn{2}{|c|}{$\begin{array}{c}\text { Stable } \\
\text { throughout }\end{array}$} & \multicolumn{2}{|r|}{ Total } \\
\hline & $\mathbf{N}$ & $\%$ TOTAL & $\mathrm{N}$ & $\%$ TOTAL & $\mathbf{N}$ & $\%$ TOTAL & $\mathrm{N}$ & $\%$ TOTAL & $\mathbf{N}$ & $\%$ TOTAL & $\mathbf{N}$ & $\%$ TOTAL & $\mathrm{N}$ & $\%$ TOTAL \\
\hline TOTAL $^{1}$ & 9 & & 11 & & 27 & & 74 & & 8 & & 466 & & 595 & \\
\hline \multicolumn{15}{|c|}{ MECHANISM OF INJURY } \\
\hline FALL & 3 & $33 \%$ & 1 & $9 \%$ & 3 & $11 \%$ & 12 & $16 \%$ & 0 & $0 \%$ & 91 & $19.5 \%$ & 110 & $18.5 \%$ \\
\hline NON-TRAUMA & 3 & $33 \%$ & 5 & $46 \%$ & 2 & $7 \%$ & 8 & $11 \%$ & 1 & $12.5 \%$ & 21 & $4.5 \%$ & 40 & $6.7 \%$ \\
\hline OTHER & 2 & $22 \%$ & 1 & $9 \%$ & 2 & $7 \%$ & 7 & $10 \%$ & 2 & $25 \%$ & 57 & $12.2 \%$ & 71 & $11.9 \%$ \\
\hline ROAD & 1 & $11 \%$ & 3 & $27 \%$ & 17 & $63 \%$ & 39 & $53 \%$ & 4 & $50 \%$ & 195 & $41.8 \%$ & 259 & $43.5 \%$ \\
\hline SPORT & 0 & $0 \%$ & 0 & $0 \%$ & 0 & $0 \%$ & 5 & $7 \%$ & 0 & $0 \%$ & 61 & $13.1 \%$ & 66 & $11.1 \%$ \\
\hline UNKNOWN & 0 & $0 \%$ & 1 & $9 \%$ & 3 & $11 \%$ & 3 & $4 \%$ & 1 & $12.5 \%$ & 41 & $8.8 \%$ & 49 & $8.2 \%$ \\
\hline \multicolumn{15}{|l|}{ TRAUMA LOCATION } \\
\hline ABDOMEN & 0 & $0 \%$ & 0 & $0 \%$ & 0 & $0 \%$ & 4 & $5 \%$ & 0 & $0 \%$ & 19 & $4.1 \%$ & 23 & $3.9 \%$ \\
\hline BURNS & 0 & $0 \%$ & 0 & $0 \%$ & 0 & $0 \%$ & 1 & $1 \%$ & 1 & $12.5 \%$ & 10 & $2.1 \%$ & 12 & $2 \%$ \\
\hline CHEST & 0 & $0 \%$ & 1 & $9 \%$ & 5 & $19 \%$ & 6 & $8 \%$ & 2 & $25 \%$ & 56 & $12 \%$ & 70 & $11.8 \%$ \\
\hline EXTREMITY & 0 & $0 \%$ & 0 & $0 \%$ & 2 & $7 \%$ & 21 & $28 \%$ & 3 & $37.5 \%$ & 212 & $45.5 \%$ & 238 & $40 \%$ \\
\hline FACE & 0 & $0 \%$ & 1 & $9 \%$ & 0 & $0 \%$ & 4 & $5 \%$ & 0 & $0 \%$ & 18 & $3.9 \%$ & 23 & $3.9 \%$ \\
\hline HEAD & 1 & $11 \%$ & 2 & $18 \%$ & 21 & $78 \%$ & 34 & $46 \%$ & 1 & $12.5 \%$ & 121 & $26 \%$ & 180 & $30.3 \%$ \\
\hline MULTI & 1 & $11 \%$ & 4 & $36 \%$ & 15 & $56 \%$ & 23 & $31 \%$ & 1 & $12.5 \%$ & 71 & $15.2 \%$ & 115 & $19.3 \%$ \\
\hline OTHER_TRAUMA & 3 & $33 \%$ & 2 & $18 \%$ & 1 & $4 \%$ & 7 & $10 \%$ & 0 & $0 \%$ & 17 & $3.6 \%$ & 30 & $5 \%$ \\
\hline PELVIS & 0 & $0 \%$ & 0 & $0 \%$ & 0 & $0 \%$ & 4 & $5 \%$ & 3 & $37.5 \%$ & 25 & $5.4 \%$ & 32 & $5.4 \%$ \\
\hline SPINAL & 0 & $0 \%$ & 0 & $0 \%$ & 0 & $0 \%$ & 3 & $4 \%$ & 0 & $0 \%$ & 98 & $21 \%$ & 101 & $17 \%$ \\
\hline \multicolumn{15}{|l|}{ NON-TRAUMA DX } \\
\hline CARDIOVASCULAR & 2 & $22 \%$ & 4 & $36 \%$ & 1 & $4 \%$ & 3 & $4 \%$ & 1 & $12.5 \%$ & 5 & $1.1 \%$ & 16 & $2.7 \%$ \\
\hline GASTROINTESTINAL & 0 & $0 \%$ & 0 & $0 \%$ & 0 & $0 \%$ & 0 & $0 \%$ & 0 & $0 \%$ & 3 & $0.6 \%$ & 3 & $0.5 \%$ \\
\hline METABOLIC & 0 & $0 \%$ & 0 & $0 \%$ & 0 & $0 \%$ & 2 & $3 \%$ & 0 & $0 \%$ & 4 & $0.9 \%$ & 6 & $1 \%$ \\
\hline NEUROLOGIC & 0 & $0 \%$ & 1 & $9 \%$ & 1 & $4 \%$ & 0 & $0 \%$ & 0 & $0 \%$ & 1 & $0.2 \%$ & 3 & $0.5 \%$ \\
\hline OTHER & 1 & $11 \%$ & 0 & $0 \%$ & 0 & $0 \%$ & 1 & $1 \%$ & 0 & $0 \%$ & 6 & $1.3 \%$ & 8 & $1.3 \%$ \\
\hline RESPIRATORY & 0 & $0 \%$ & 0 & $0 \%$ & 0 & $0 \%$ & 2 & $3 \%$ & 0 & $0 \%$ & 1 & $0.2 \%$ & 3 & $0.5 \%$ \\
\hline
\end{tabular}

$\mathrm{N}=1$ missing

HEMS in NSW in transport to the receiving hospital. During patient transport, HEMS in NSW often bypass the nearest designated trauma hospital as part of the local regionalised trauma care system. Patients transported by HEMS during primary scene responses were predominantly judged to be clinically stable.

Around the world, HEMS operate in many different settings including urban, rural and remote environments. We found HEMS in NSW predominantly operated in areas classified as 'major cities' or 'inner regional' although differences existed between the urban and regional based HEMS. For HEMS in regional areas, we found on average a two-fold increase in the average distance travelled relative to the trauma hospital, compared to the metropolitan HEMS. Such differences suggest variance in the benefits of HEMS in NSW which includes improving health service equity in regional areas and providing a 'second tier' of support in urban areas. Locations of HEMS in NSW are historically determined and given the large distances travelled by HEMS in NSW, further research is needed into the most appropriate HEMS locations relative to need.

Our results regarding distances travelled by HEMS in regional areas are consistent with previous research in NSW [18]. Compared to a meta-analysis from the US of HEMS pre-hospital care times for trauma [19], our results showed HEMS in NSW have longer times in all categories. This discrepancy may reflect several features of the local system such as the large distances travelled to the scene and the use of physicians as opposed to paramedics (which are predominantly used in US HEMS). A recent analysis from California showed over $60 \%$ of HEMS primary scene responses were within 29 miles $(\sim 47 \mathrm{~km})$ of the receiving hospital [20]. This compared to approximately $40 \%$ of missions within the same distance in our analysis. Compared to European 
HEMS, which are predominantly physician staffed, our NSW transport times were also longer with HEMS transport times to the receiving hospital in the Netherlands reported as a mean of $13 \mathrm{~min}$ [21]. This compared to a mean of $30 \mathrm{~min}$ in our study.

Our results also showed HEMS in NSW attend a large diversity of trauma incidents including road trauma, falls, sports injuries and a small proportion of patients classified as non-trauma. The predominance of road trauma reported in our study is similar to previous findings in other jurisdictions [22-24] although the proportion of incidents was slightly less than that previously reported in NSW $[18,25]$. The majority of patients attended by HEMS were assessed to be clinically stable and had normal physiology, although data limitations precluded a true assessment of illness severity. Previous research has documented high over-triage rates in HEMS primary scene responses [26]. Given the expense of HEMS in NSW [12], there is scope for further research into the accuracy of current dispatch criteria in NSW to ensure HEMS are targeted to appropriate patients.

An important finding in our study was the high proportion of missions that bypassed the closest designated trauma hospital. This highlights a seldom-mentioned advantage of HEMS which incorporates the crew's ability to exercise clinical judgment and take patients to appropriate hospitals without being restricted by road networks or travel time. In practice this includes burns and spinal trauma as well as paediatric patients being transferred to specialised hospitals where definitive specific care can be provided. HEMS also bypassed lower grade trauma hospital in order to take patients to major trauma hospitals that can provide clinical services such as interventional radiology, cardiothoracic surgery and neurosurgery. We also noted a lower probability of hospital bypass by regional HEMS, which may have reflected patients who do not require neurosurgery or cardiothoracic surgery being taking to regional trauma services, as would be appropriate. More broadly, the high proportion of HEMS bypass reflects HEMS in NSW functioning as part of a regionalised trauma care system that has been shown to reduce mortality $[27,28]$.

Previous studies evaluating the effect of HEMS on patient mortality, have predominantly compared HEMS to a direct scene transport via ground $[7,8]$. In the NSW jurisdiction, our findings regarding distances travelled and the frequency of hospital bypass, highlight that HEMS are likely to replace ground transport to a regional hospital in some instances. Depending on patient acuity, this may be followed by stabilisation and subsequent transport to a major trauma hospital. Hence, when examining the economics of HEMS transports, future studies need to consider the appropriate alternative to HEMS and the full "opportunity cost" of withholding HEMS.

\section{Limitations}

Due to inconsistent data collection we were unable to include four 'regional' HEMS which undertake primary scene responses in NSW in this analysis. In future this limitation will be addressed through the introduction of a state wide uniform HEMS database (Air Maestro). The HEMS that we were able to include are representative of both metropolitan and regional HEMS activities and together are responsible for approximately half of the total HEMS primary scene response activities in NSW [12]. The service excluded from our study (Metro2), operated in predominantly urban areas for the sole purpose of a clinical trial of rapid responses to head injured patients. Although by omitting this service the reported number of patients attended by HEMS in the study period with head injuries and (other factors) is likely to be underestimated, the unique nature of the Metro2 service during the study period meant the data would not be representative of traditional HEMS in the state.

Given the resource implications of using HEMS, robust service data collection is essential to investigate HEMS efficiencies and patient impact. As part of our findings, we identified several limitations in the service databases which can be addressed to improve the validity of future studies. This included omitted variables and the internal validity of collected data. In terms of omitted variables; we were unable to calculate HEMS times relative to the time of injury, however our results still provide an accurate reflection of the time taken to complete HEMS missions from activation. Data limitations also precluded the identification of patient entrapment which would have extended scene time in certain cases. Internal validity is also an issue in the data we report; as we were unable to verify data accuracy. Variables such as patient diagnosis and clinical condition rely on the opinions of multiple clinicians which may include inconsistencies. To address this issue, future database reconfiguration could consider linkage to hospital trauma registries to gain more accurate information on patient diagnosis, injury severity and outcomes.

\section{Conclusion}

Assessing the benefit of HEMS in primary scene responses is difficult as HEMS encompasses a 'package' of interventions including improved access, speed and advanced clinical skills and decision making, which is known to vary between regions. Describing the characteristics of HEMS missions and patients in the local environment is an important step in understanding how HEMS benefit the health system. Our results document the time HEMS take to activate, respond to the scene, 
treat and transport patients as well as the proximity of HEMS operations to the receiving hospital and the clinical characteristics of patients attended. The high proportion of hospital bypass is a seldom mentioned benefit of HEMS and this finding has implications for future studies assessing the true benefit a HEMS provides. Importantly, our results highlight many areas for future research to ensure HEMS are used efficiently and appropriately.

\section{Abbreviations \\ HEMS: Helicopter Emergency Medical Service; GIS: Geographic Information Systems; GCS: Glasgow Coma Score; RTS: Revised Trauma Score.}

\section{Competing interests}

The authors declare that they have no competing interests.

\section{Authors' contributions}

$C T$ conceived this study, carried out the statistical analysis and drafted the original manuscript. BL provided assistance with statistical analysis and reviewed the manuscript. EB undertook geographical mapping and reviewed the manuscript. BB, SJ and JM provided clinical and health service expertise and reviewed the manuscript. All authors read and approved the final manuscript.

\section{Acknowledgments}

The authors would like to acknowledge the contribution of staff in the Greater Sydney Area HEMS who collected the data presented in this manuscript.

\section{Author details}

'The George Institute for Global Health, PO Box M201, Missenden Rd Camperdown, NSW 2050, Sydney, NSW, Australia. ${ }^{2}$ The University of Sydney, Sydney Medical School, Sydney, NSW, Australia. ${ }^{3}$ The University of NSW, Faculty of Medicine, Sydney, NSW, Australia. ${ }^{4}$ The University of Sydney, School of Geosciences, Sydney, NSW, Australia. ${ }^{5}$ Greater Sydney Area HEMS, Ambulance Service of NSW, Sydney, NSW, Australia.

Received: 3 August 2012 Accepted: 8 November 2012

Published: 15 November 2012

\section{References}

1. NSW Health Critical Care Tertiary Referral Networks \& Transfer of Care (Adults). http://www.health.nsw.gov.au/policies/PD/2010/PD2010_021.html.

2. NSW Department of Health Selected Specialty and Statewide Development Branch: NSW Trauma Services, Selected specialty and statewide service plans no 6. NSW: Health; 2009 .

3. Ambulance Service of New South Wales: Protocol T3: Helicopter Operations Severe Trauma - "Primary Response". Sydney: Ambulance Service of NSW; 2008:1-7.

4. Ambulance Service of New South Wales: Protocol T1 - Pre-hospital management of major trauma. Sydney: Ambulance Service of NSW; 2008:1-2.

5. Taylor CB, Stevenson M, Jan S, Middleton PM, Fitzharris M, Myburgh J: A systematic review of the cost and benefit of helicopter emergency medical services. Injury 2010, 41:10-20.

6. Taylor CB, Jan S, Curtis K, Tzannes A, Li Q, Palmer C, Dickson C, Myburgh J: The cost-effectiveness of physician staffed Helicopter Emergency Medical Service (HEMS) transport to a major trauma centre in NSW, Australia. Injury 2012, Accepted 20/07/2012, in press.

7. Butler DP, Anwar I, Willet $\mathrm{K}: \mathrm{Is}$ it the $\mathrm{H}$ or the EMS in HEMS that has an impact on trauma patient mortality? A systematic review of the evidence. Emerg Med J 2010, 27:692-701.

8. Ringburg AN, Thomas SH, Steyerberg EW, van Lieshout EMM, Patka P, Schipper IB: Lives saved by helicopter emergency medical services: an overview of literature. Air Med J 2009, 28(6):298-302.

9. Thomas SH: Helicopter emergency medical services transport outcomes literature: annotated review of articles published 2000-2003. Prehosp Emerg Care 2004, 8(3):322-333.
10. Thomas SH: Helicopter EMS transport outcomes literature: annotated review of articles published 2004-2006. Prehosp Emerg Care 2007, 11(4):477-488.

11. Thomas SH, Biddenger PD: Helicopter trauma transport: an overview of recent outcomes and triage literature. Curr Opin Anaesthesiol 2003, 16:153-158.

12. Taylor CB, Stevenson M, Jan S, Liu B, Tall G, Middleton PM, Fitzharris M, Myburgh J: An investigation into the cost, coverage and activities of Helicopter Emergency Medical Services in the state of New South Wales, Australia. Injury 2011, 42:1088-1094.

13. CareFlight Head Injury Retrieval Trial (HIRT). http://careflight.org/medical/hirt/.

14. Glover J, Tennant S: Remote Areas Statistical Geography in Australia - Notes on the Accessibility/Remoteness Index for Australia (ARIA+version), Working paper series no 9. Adelaide, SA: Public Health Information Development Unit; 2003.

15. Knaus WA, Wagner DP, Draper EA, Zimmerman JE, Bergner M, Bastos PG, Sirio CA, Murphy DJ, Lotring T, Damiano A, et al: The APACHE III prognostic system. Risk prediction of hospital mortality for critically ill hospitalized adults. Chest 1991, 100(6):1619-1636.

16. Teasdale G, Jennett B: Assessment of coma and impaired consciousness. A practical scale. Lancet 1974, 2(7872):81-84.

17. Champion HR, Sacco WJ, Copes WS, Gann DS, Gennarelli TA, Flanagan ME: A revision of the trauma score. J Tribol-T Asme 1989, 29(5):623-629.

18. Sheperd M, Trethewy C, Kennedy J, Davis L: Helicopter use in rural trauma. Emerg Med Australas 2008, 20:494-499.

19. Carr BG, Caplan JM, Pryor JP, Branas CC: A meta-analysis of prehospital care times for trauma. Prehosp Emerg Care 2006, 10(2):198-206.

20. Diaz MA, Hendey GW, Bivins HG: When is the helicopter faster? A comparison of helicopter and ground ambulance transport times. J Trauma 2005, 58(1):148-153.

21. Frankema SP, Ringburg AN, Steyerberg EW, Edwards MJ, Schipper IB, van Vugt AB: Beneficial effect of helicopter emergency medical services on survival of severely injured patients. Br J Surg 2004, 91(11):1520-1526.

22. Marinangeli F, Tomei M, Ursini ML, Ricotti V, Varrassi G: Helicopter emergency medical service in Italy: reality and perspectives. Air Med J 2007, 26(6):292-298.

23. Melton JTK, Jain S, Kendrick B, Deo SD: Helicopter Emergency Ambulance Service (HEAS) transfer: an analysis of trauma patient case-mix, injury severity and outcome. Ann R Coll Surg Engl 2007, 89(5):513-516.

24. Mitchell AD, Tallon JM, Sealy B: Air versus ground transport of major trauma patients to a tertiary trauma centre: a province-wide comparison using TRISS analysis. Can J Surg 2007, 50(2):129-133.

25. Lee A, Garner A, Fearnside M, Harrison K: Level of prehospital care and risk of mortality in patients with and without severe blunt head injury. Injury 2003, 34(11):815-819.

26. Bledsoe BE, Wesley AK, Eckstein M, Dunn TM, O'Keefe MF: Helicopter scene transport of trauma patients with nonlife-threatening injuries: a metaanalysis. J Trauma 2006, 60(6):1257-1265.

27. Brennan PW, Everest ER, Griggs WM, Slater A, Carter L, Lee C, Semmens JK, Wood DJ, Nguyen A-MT, Owen DL, et al: Risk of death among cases attending South Australian major trauma services after severe trauma: the first 4 years of operation of a state trauma system. J Trauma 2002, 53(2):333-339.

28. Cameron PA, Gabbe BJ, Cooper DJ, Walker T, Judson R, McNeil J: A statewide system of trauma care in Victoria: effect on patient survival. Med J Australia 2008, 189(10):546-550.

\section{doi:10.1186/1472-6963-12-402}

Cite this article as: Taylor et al:: Primary scene responses by Helicopter Emergency Medical Services in New South Wales Australia 2008-2009. BMC Health Services Research 2012 12:402. 